\title{
Less complex language, more participation: how consultation documents shape participatory patterns
}

\author{
Simon Fink ${ }^{1}$ (D) Eva Ruffing ${ }^{2} \cdot$ Tobias Burst $^{3} \cdot$ Sara Katharina Chinnow $^{1}$
}

Accepted: 25 May 2021 / Published online: 10 June 2021

(c) The Author(s) 2021

\begin{abstract}
Consultations are thought to increase the legitimacy of policies. However, this reasoning only holds if stakeholders really participate in the consultations. Current scholarship offers three explanations for participation patterns: Institutional rules, policy characteristics, and interest group resources determine participation. This article argues that additionally the linguistic complexity of consultation documents influences participation. Complex language deters potential participants, because it raises the costs of participation. A quantitative analysis of the German consultation of electricity grids lends credibility to the argument: If the description of a power line is simplified between two consultation rounds, the number of contributions mentioning that power line increases. This result contributes to our understanding of unequal participation patterns, and the institutional design of participatory procedures. If we think that legitimacy is enhanced by broad participation, then language of the documents matters.
\end{abstract}

Keywords Language $\cdot$ Participation $\cdot$ Consultations $\cdot$ Text analysis $\cdot$ Written statements $\cdot$ Citizens

Simon Fink

simon.fink@sowi.uni-goettingen.de

Eva Ruffing

eva.ruffing@uni-osnabrueck.de

Tobias Burst

tobias.burst@wzb.eu

Sara Katharina Chinnow

s.chinnow@stud.uni-goettingen.de

1 Georg-August-Universität Göttingen, Platz der Göttinger Sieben 3, 37073 Göttingen, Germany

2 Universität Osnabrück, Seminarstr. 33, 49074 Osnabrück, Germany

3 Wissenschaftszentrum Berlin für Sozialforschung, Reichpietschufer 50, 10785 Berlin, Germany 


\section{Introduction}

Consultations are an integral part of policymaking. Organizations like the European Commission, national governments, or local communities routinely ask for the input of stakeholders. The hope is that civil society contributes information to decisions, thereby enhancing output- and input legitimacy (Arras and Braun 2018; Hermansson 2016).

However, there is a debate on the pattern of participation, that is, how many and what kind of actors participate in consultations. Normative reasoning argues that consultations should attract all kinds of stakeholders to generate input legitimacy (Smith 2009, 20-21). Output legitimacy is also affected: If there is no broad participation in consultations, there is a risk of agency capture (Beyers and Arras 2019; Yackee and Yackee 2006). Thus, the research question is: What determines how many and what kind of actors participate in consultations?

The current literature either focuses on institutional features of the consultation, on the characteristics of the participants, or on the salience of the topic to explain variation in participatory patterns. Many studies find a dominance of business interests (Hermansson 2016), conditioned by policy characteristics (Rasmussen and Carroll 2014), or the access rules (Beyers and Arras 2019; Pakull et al. 2020). Most arguments are grounded in a rational actor model, with potential participants calculating the costs and benefits of consultation participation (Røed and Wøien Hansen 2018; Sjoberg et al. 2017).

We argue that the linguistic properties of consultation documents also influence the costs and benefits of consultations, and should hence be part of a rational framework. These documents outline the context and the purpose of the consultation: The proposed policy, the questions on which stakeholders can comment, and the formal requirements (e.g., deadlines).

Our reasoning is directly derived from the rational actor model: Complex documents generate "cognitive transaction costs" (Hurka and Haag 2019), raise the costs of participation and alter the beliefs about the efficacy of a consultation contribution (Sjoberg et al. 2017). Thus, the more complex consultation documents are, the less responses they generate. However, this reasoning applies only to potential participants with little resources, such as citizens. Well-organized interests, such as business groups, have resources to process complex documents and draft consultation responses. Thus, our argument is about the language used in consultations, but not about language as the medium of social construction (Saurugger 2010). Instead, we conceptualize language in terms of costs and benefits.

We study German electricity grid planning as a case. Electricity grid expansion is contentious in Germany, as citizens do not want power lines close to their homes. To increase acceptance of grid expansion, the German legislator has institutionalized major consultations. Each planned power line is described in consultation documents by the transmission system operators (TSOs), and citizens and stakeholders can submit comments (Steinbach 2013). The consultation process is repeated annually or every two years. 
Infrastructure planning is on the one hand a special case, as the policy field is highly complex. However, the ambition of consultations is to engage a broad variety of stakeholders in policymaking processes that were for a long time the domain of specialists. In that regard, infrastructure planning stands pars pro toto for a whole range of complex policy fields that are opened up to consultation procedures.

We generated a dataset that contains as an independent variable the complexity of the description of each power line (i.e., the proposed policy), measured using Lix readability scores (Bischof and Senninger 2017), and as a dependent variable the number of contributions that each power line receives by different types of actors. We estimate regression models to elucidate whether the complexity of the description is related to the number of contributions the power line receives.

On the one hand, this case precludes broad generalizability-electricity grid construction is a technical policy field. On the other hand, our design allows us to control for many factors that are thought to influence participation. Most importantly, the iterated nature of the consultation allows us to estimate a dynamic model: Does the number of contributions to the same power line change if the verbal description of that power line is changed?

The first result is that the TSOs-the actors conducting the consultationwrite very complex documents. However, over successive iterations of the consultation, the TSOs simplify their documents. Second, making the description of a power line more readable increases the number of contributions that mention this power line. Third, we find mixed evidence for the proposition that complex documents mainly deter citizens' contributions. On balance, it seems that many types of actors profit from easier documents and are more likely to contribute to the consultation.

This result has implications for several debates. First, for the German case of grid planning, the conclusion is that the consultation procedure is in principle open for everybody, but in practice, contributors only comment on those power lines that are described in not-too-complex language. Thus, our contribution joins the critical assessments of the procedure. The procedure may formally be a consultation of all planned power lines, but de facto, it is a consultation on the power lines that are described in easier language. Second, our result speaks to current research on language and politics. We support the argument that linguistic properties of political documents have an impact on politically relevant outcomes (Bischof and Senninger 2017; Hurka and Haag 2019; Røed and Wøien Hansen 2018). Third, more specifically for interest group research, we open up an interesting venue. This research has focused on the consultation institutions, on the properties of the consulted policy or the characteristics of the participants to explain biases in participation. Our results suggests that even given the same context factors and the same policy complexity, the linguistic complexity of the consultation documents makes a difference.

The article is structured as follows: The next section discusses the literature on consultation participation, identifies the research gap, and derives hypotheses. The third sections outlines our case and the research design. The fourth section comprises the empirical analysis. Section five concludes. 


\section{Theory: Who participates in consultations?}

Consultations are a cornerstone of current policymaking (OECD 2001). All kinds of actors tasked with policymaking reach out to civil society. The expectations are high: Consultations are thought to allow societal preferences to flow more directly into policymaking, and hence increase input legitimacy (Bunea 2017, 50; Kohler-Koch and Finke 2007). Additionally, the quality of policies may increase because of the information gathered in consultations. Hence, the output legitimacy may increase (Bouwen 2002, 371). Alternatively, one may see consultations as a means to ensure throughput legitimacy, that is, as an instrument to ensure an open and transparent policymaking process (Arras and Beyers 2020; Schmidt 2012 , 14). No matter to which legitimatory "promise" one subscribes, the idea is that well-designed consultations increase the democratic quality of political decisions.

Combining normative political theory with empirical analysis, there is a lively debate on how many actors participate in consultations, and how diverse the set of participating actors is. The literature originates in different debates-democratic theory, theories of lobbying, or interest group research-and studies different levels of government-ranging from local administrations to international organizations-but there are some common threads. We can group the literature into three strands that see the determinants of participation in either the characteristics of the participating actors, the characteristics of the policies consulted, or the institutions that structure the consultation.

The common thread of the literature is that potential consultation participants are seen as rational, calculating the benefits and costs of participating (Pakull et al. 2020; Røed and Wøien Hansen 2018; Sjoberg et al. 2017).

First, the literature on group characteristics argues that some groups can bear the costs of participating easier than others. Resourceful actors such as business actors have less costs participating in consultations as they already have expertise (Klüver 2013; Yackee and Yackee 2006). In particular for the European level, a well-established result is that consultations are biased toward the participation of well-resourced business groups (Heidbreder 2015) that offer valuable information (Hermansson 2016; Klüver 2013). The literature on regulatory rulemaking in the US paints a similar picture. With some qualifications, the overall argument is that resourceful actors, predominantly economic interest groups, are over-represented (Balla 1998; Yackee and Yackee 2006).

A second line of reasoning argues that properties of the topic under consideration influence the pattern of participation. The main properties theorized are the technical complexity and the salience of the issue. For example, technical policy fields are thought to have a bias toward business, as the costs of drafting well-informed and technically appropriate contributions are high (Broscheid and Coen 2007; Rasmussen and Carroll 2014, 447; Pagliari and Young 2015). Distributional issues are less affected by participation bias than regulatory issues, and salience of an issue increases participation, as a salient topic means larger benefits that may outweigh the participation costs (Rasmussen et al. 2014, 253-254; 
Røed and Wøien Hansen 2018, 1450). However, an interaction argument claims that salience of an issue only increases civil society participation if the policy is not too complex (Røed and Wøien Hansen 2018).

A third line of reasoning attributes different participation patterns to different consultation institutions that increase or decrease participation costs. Again using the EU as an empirical example, the literature argues the European Commission strategically design consultations to have higher or lower entry costs (Arras and Beyers 2020; Arras and Braun 2018; Bunea and Thomson 2015; Van Ballaert 2017). In that way, they can influence the quantity and type of actors participating, and thereby influence the quantity and type of information they obtain (Broscheid and Coen 2007). Online consultations are seen as a relatively low-cost format that generates a broad variety of input (Beyers and Arras 2019; Rasmussen and Carroll 2014, 449), and makes the EU consultation system more transparent (Bunea 2017).

Our article highlights a cost that has up to now been neglected in the literature: the linguistic complexity of the consultation documents. ${ }^{1}$ The argument is that stakeholders have to understand what the consultation is all about: What the proposed policy or decision is, on what aspects of the policy input is sought, what aspects of the policy are outside the scope of the consultation, and what the formal requirements for participation are.

Linguistic complexity of the consultation impacts on the cost-benefit calculation of potential consultation participants in two ways. First, complex consultation documents require more time to read and process. The literature on EU legislation shows that the more complex a document is formulated, the more cognitive transaction costs it takes to engage with the document and to grasp the policy implications (Hurka and Haag 2019). A similar reasoning applies to consultation documents. The more complex their language, the higher are the costs reading and understanding them, and of drafting an adequate response. Second, and related, Sjoberg et al. (2017) argue that the perceived efficacy of a contribution influences whether an actor participates in a consultation. If a stakeholder thinks her contribution will make a difference, she will participate. A consultation document that is linguistically complex will presumably decrease the belief that one's own contribution will have an impact, as it is not clear what kind of arguments influence the decision and whether one has good arguments at all. Thus, hypothesis 1 states that linguistically complex consultation documents will generate fewer responses.

Hypothesis 1 The more linguistically complex consultation documents are, the less contributions they attract.

Returning to the resource argument made at the outset of the discussion, we can qualify hypothesis 1 . Complex language of consultation documents makes it more costly to participate in consultations. However, this argument mostly applies to

\footnotetext{
1 There are studies assessing the linguistic complexity of consultation documents (Beyers and Arras 2019; Pagliari and Young 2015; Røed and Wøien Hansen 2018), but they use linguistic complexity as a proxy for technical complexity of the policy.
} 
actors with little resources, predominantly citizens. Organized interests are used to working with complex documents and have expert staff (Klüver 2013; Yackee and Yackee 2006). Our analysis should be sensitive to this variation in the actor pool and check whether the hypothesis holds for all kinds of actor groups. Presumably, the number of citizen contributions will drop with increasing complexity of documents. For other actor types, it is an open empirical question whether they can cope with linguistic complexity.

The null hypothesis against which our hypothesis competes is that linguistic complexity has no influence on participation patterns. The rational choice argument posits that linguistic complexity figures in actors' calculations. But that need not be the case. Maybe we have a selection effect: Actors that are interested in consultations may already have a high level of textual competence and parsing consultation documents generates zero costs. Alternatively actors may just think they have understood the text and draft a contribution. In both cases, linguistic complexity does not matter.

If the threshold for participation is low (as in online consultations), there might be less concerns about efficacy. Stakeholders might be content with signaling their position, notwithstanding the actual prospects of success. For some organizations, the signal that they have contributed may be more important than the actual content of the contribution. Thus, it is not self-evident that linguistic complexity has an impact. Instead, it is an empirical question whether linguistic complexity matters.

We do not claim that linguistic properties of the consultation documents are the most important factor influencing participation patterns. Arguably, the factors outlined above-salience, technical complexity, institutions, group characteristics-are more important. However, we argue that linguistic properties of the documents also matter. Moreover, while many of the factors outlined above can hardly be influenced by the consulting organization, the verbal description of the issues at stake can be influenced by the consulting organization. If our reasoning is correct, organizers of a consultation may be able to either attract more citizens to a consultation by using simpler language, or try to discourage citizen participation by using obscure language.

\section{Case, research design and methods}

To assess our hypotheses, we use the German consultation of electricity power lines as a test case. One the one hand, this case has some features that allow us to hold the factors that are thought to influence participation patterns constant and focus on linguistic complexity. On the other hand, the generalizability of our results may be impaired.

The four German Transmission Systems Operators (TSOs) Amprion, Tennet, TransnetBW, and 50Hertz conduct consultations when planning grid projects. The planning regime is part of the German 'Energiewende', a process through which Germany endeavors to transform its energy system to renewable energies. The topic is politically salient: In order transform the German energy system to renewable energies, high-voltage lines are needed. However, which lines are needed is contentious. The process of determining the need for power lines is technical. Justifications 
of the need for new power lines must be based on elaborate simulations of the whole energy system and its interdependencies. The simulations build on a large number of assumptions about energy production and consumption, such as cost of different fuels, consumer behavior, or diffusion of electromobility. On the other hand, the immediate costs for the affected region are easy to grasp: Power lines are huge infrastructures that threaten the landscape, lower the value of adjacent houses, and elicit fears of health problems. Thus, local resistance is considerable (Steinbach 2013), and the legislator sought a way of increasing public acceptance.

The demand planning procedure is repeated annually or biennially, and the same power line can be consulted multiple times. ${ }^{2}$ The purpose of the planning is to assess which power lines are needed in the next ten years.

First, the TSOs develop a draft for the network development plan (NDP) based on assumptions about energy production. This NDP is the consultation document we are interested in, and central to our argument. The NDP defines which places in Germany need to be connected by power lines. Each TSO_as a regional monopolydescribes the power lines planned for its region. If a power lines affects two or more regions, the responsible TSOs jointly write the description. The texts describing the power lines have a standardized format: The power line and its technical properties are described. A map indicates the affected geographical area. The justification of the need for the power line is often quite elaborate, based on the shortcomings of other power lines, the change of electricity production structure (expected shutdown of atomic power plants, increase of renewable energies), and overall electricity market development (impact on the European market, security of supply). These justifications are backed up with capacity data, and often accompanied by a description why the chosen power line is the only viable alternative among several taken into consideration. The first draft of this plan is open for consultation, and the TSOs have to take the public's submissions into account when revising the plan. Second, this draft is submitted to the Federal Network Agency (FNA) for the further approval procedure. $^{3}$

\footnotetext{
2 The consultation was first conducted in 2012, then 2013, and 2014. In 2015, the German legislator changed the feed-in tariff system for renewable energies, and the demand-planning procedure was halted midway, because the assumptions about energy production had to be revised. Moreover, all stakeholders agreed that an annual schedule was too tight, and agreed on a biennial consultation. We have data for 2012, 2013, 2014, and 2017.

${ }^{3}$ The planning regime is legally mandated and regulated. The private TSOs-most of them former stateowned companies, and still endowed with regional monopolies-act as agents of a government-led planning process. The German government delegates the planning of electricity grids to the Federal Network Agency, which in turn delegates the drafting of network plans to the TSOs, as they are the technical experts (Fink and Ruffing 2019). Hence, the TSOs are formally private entities, but when planning networks and consulting the network plans, they act as public utilities under legal obligations.
} 
The interesting feature for our purpose is that a considerable number of power lines is proposed multiple times over the years. ${ }^{4}$ Their technical properties and geographical location remain largely the same, the only thing that changes is their verbal description.

The concrete case of electricity power lines and its technical nature should not obscure the fact that, in essence, we have a common consultation procedure, similar to many others ${ }^{5}$ : An actor legally tasked with putting forward policy proposals is describing these policy proposals and their justifications in a document. Each year, the consulting actor presents a list of proposals, stakeholders react, and the proposals are checked in an administrative procedure. The next year, the consulting actor again presents a list of policy proposals-some new and some re-phrased versions of the old proposals - and the public can again react. ${ }^{6}$

This allows us to hold many factors that are thought to influence participation constant or control for them. The institutional rules for participation are the same over the years: Everybody is allowed to submit contributions online, which makes the procedure a most likely case for broad participation, because the transaction costs of submitting the contribution are low (Beyers and Arras 2019; Røed and Wøien Hansen 2018). The complexity of the policy is also constant. One may argue that some power lines-for example the "electricity highway" lines that cut through the whole of Germany - are technically more complex than others, but on the whole, the complexity of the policy field is constant. ${ }^{7}$ Moreover, the iterative nature of the procedure allows us to have a dynamic perspective: If the same power line is presented again in re-phrased language, does the number of contributions that address this power line change? ${ }^{8}$

Our dependent variable is the number of contributions that refer to a specific power line. We created a dataset with the full-text of all contributions to the consultations of the TSOs, scraped from the consultation website. ${ }^{9}$ Then, we used dictionary coding to code which power lines are mentioned in the contribution. This procedure is helped by the fact that the power line descriptions are standardized and

\footnotetext{
${ }^{4}$ Each proposed power line is evaluated anew each year. This applies to the power lines that were approved and the power lines that were rejected by the FNA. The former have to be re-evaluated in light of the assumptions about energy production and consumption, the latter can be re-applied. A power line is dropped from the plans if either the TSOs do not see it as necessary anymore, or if the power line enters the next planning stage, looking for a concrete route. The idea is to have a dynamic planning process that closely follows the development of renewable energies.

5 Think of the regulation of genetically modified organisms (Ferretti and Lener 2008), the financial sector (Pagliari and Young 2015), or medicines (Beyers and Arras 2019). In the abstract, we have a set of highly technical policy proposals, backed up by data-driven justifications.

6 Previous research has shown that the proposals are often re-phrased and the descriptions are changed, but there are very few to none substantial changes of the proposals.

7 Moreover, we control for the technical properties of the power lines using appropriate control variables.

${ }^{8}$ An interesting question is whether other things change over time due to the iterated nature of the procedure. Empirically, we see that the content of the contributions become better over time due to policy learning if stakeholders participate multiple times (Fink and Ruffing 2020). However, the overall institutional setup of the consultation remained the same over time.

9 www.netzausbau.de.
} 
Table 1 Descriptive statistics of the main dependent and independent variable

\begin{tabular}{llllllc}
\hline Variable & & Mean & Std. Dev & Min & Max & Observations \\
\hline No. of contributions & Overall & \multirow{2}{*}{72.17} & 513.48 & 0 & 7416 & $N=256$ \\
& Between & & 198.25 & 0 & 1914.50 & $n=132$ \\
& within & & 439.51 & 1827.32 & 5573.67 & T-bar $=1.93939$ \\
Complexity of text & Overall & 64.58 & 4.18 & 52.92 & 79.50 & $N=258$ \\
(Lix) & Between & & 3.498 & 54.70 & 79.04 & $n=134$ \\
& within & & 2.56 & 55.95 & 75.17 & T-bar $=1.92537$ \\
\hline
\end{tabular}

contain a project code as well as the start and the endpoint of the power line. These terms form our dictionary for detecting which power lines are mentioned in a contribution. A single contribution can refer to one power line, to no power line at all (if it only contains general remarks about energy policy), or mention multiple power lines.

Table 1 gives an overview over the dependent variable. Some power lines do not receive any comments, others are receive more than 100 comments. However, note that we have one major outlier in the data: In 2014, one power line received 7416 comments, most of which were form letters that citizens only had to sign. We have decided to exclude this power line from our models, as it is not our ambition to model this extraordinary form of mobilization. We aim to explain the usual variation of contributions and simply cannot account for one special event.

To assess whether our hypothesis is valid for all kinds of actors, we used a dictionary to code which type of actor submitted a given contribution. Based on a list of the names of the organizations, we differentiated the following types of actors: Citizen, citizens' initiative, company, industry association, municipalities, Länder government, and districts. ${ }^{10}$

Our independent variable is the linguistic complexity —or readability-of the power line description. To assess this variable, we use the Lix readability score (Björnsson 1968). This measure has been transferred to the social sciences to assess the readability of political speeches and ministerial websites, and party manifestos The Lix score assesses both the complexity of words as well as the complexity of sentences. The formula is as follows:

$$
L I X=\frac{W}{S_{t}}+\frac{100 \times W_{7 c}}{W}
$$

$W$ denotes the number of words in a project description, $S_{t}$ denotes the number of sentences, and $W_{7 \mathrm{c}}$ the number of words with seven or more letters. In essence, the complexity of a text increases (and the readability decreases), if a text contains many long sentences and/or long words. Note that the number of sentences and the

\footnotetext{
10 Table 6 in the appendix shows the breakdown of submissions per power line and actor type. The bulk of the submissions come from citizens.
} 
number of words function as denominators, that is, longer texts are not necessarily less readable. On the contrary, splitting up a given number of words in more sentences or using more short words in relation to the longer words makes a text more readable according to the formula.

We choose the Lix as our main operationalization for several reasons. First, the measure has shown its applicability to German political texts, while party manifestos (Bischof and Senninger 2017) and ministerial websites (Kercher 2013), might not be exactly the same type of texts as consultation documents, especially the study of Kercher $(2013$, 368, 389-391) is helpful. He shows that the Lix score performs well to predict subjective and objective understanding of German-language political texts, such as policy proposals outlined on ministerial websites. Second, the oftenused Flesch-Kincaid score for English texts is less suited for German texts, mostly because its measure of word length fits less well to the linguistic properties of the German language (Bamberger and Vanecek 1984, 56).

While the Lix is our main operationalization of readability, we alternatively use two measures that have either been specifically developed for or adapted to German texts: The simple measure of gobbledygook (SMOG) in its German version and the Neue Wiener Sachtextformel (NWS) (Bamberger and Vanecek 1984). The NWS is a more complex measure than the Lix, including the number of polysyllabic words, sentence length, number of long words (more than six characters), and words with only one syllable. The SMOG, on the other hand, is simpler and based on number of words with more than three syllables. Thus, in terms of complexity of measurement, we opt for a middle ground, but test the robustness of our results using one measure taking into account more, and one measure taking into account less textual features.

A text with Lix score of larger than 60 is deemed very difficult to read (Björnsson 1968). Bischof and Senninger have calculated the Lix scores for well-known German texts: The tabloid "Bild" has a mean Lix of $\sim 40$, while the works of Jürgen Habermas are above 60 . The party manifestos analyzed by Bischof and Senninger are between 52 and 58 (Bischof and Senninger 2017, 481). Kercher (2013, 322) calculated the Lix score for texts on the webpages of German ministries and found a Lix between 60 and 67 . With these rough comparisons in mind, we can have a look at our independent variable.

Table 1 shows that the TSOs write very complex policy descriptions. The readability of the power line descriptions is similar to that of German ministry website, which is a plausible result and increases our trust in the validity of the measure.

Other authors have used readability of documents to measure policy complexity. Either using similar readability scores (Røed and Wøien Hansen 2018, 1454), or hand-coding of linguistic complexity into categories (Beyers and Arras 2019, 12; Pagliari and Young 2015), these authors assume that linguistic complexity measures policy complexity over different policy fields. However, our data show that in a policy field that is marked by relatively similar policy complexity, policies may be described in different levels of linguistic complexity.

There are other reasons besides the complexity of the verbal description why a power line receives more contributions than others, for example geography, mobilization potential, or partisan support for protest. We cannot model all of these factors. To control for these factors, we use the logic of the consultation: Over the years, the 
Table 2 Number of power lines under consultation per year

\begin{tabular}{llllll}
\hline & \multicolumn{2}{l}{ Year } & & & \\
\cline { 2 - 6 } & 2012 & 2013 & 2014 & 2017 & Total \\
\hline $\begin{array}{l}\text { New under } \\
\quad \text { consultation }\end{array}$ & & 31 & 45 & 48 & 124 \\
Yes & 39 & 17 & 27 & 51 & 134 \\
Total & 39 & 48 & 72 & 99 & 258 \\
\hline
\end{tabular}

TSOs propose more power lines, but several power lines are repeatedly consulted. Of the 39 power lines consulted in the first plan, 31 were consulted again in 2013, of the 48 power lines that were consulted in 2013, 45 were consulted again in 2014, and so on (see Table 2). We exploit this feature of the consultation for our research design: It allows us to track a number of power lines over time (which translates to: holds the policy constant) and compare how a change in their verbal description is related to a change in the number of contributions they receive.

Thus, we model the change of the number of submissions to a given power line since the last consultation as a function of the change of the linguistic complexity of the project description. This strategy decreases the number of observations we can use, because we need power lines that were mentioned in 2012 and 2013, 2013 and 2014, and so on, to model this change. For example, the 51 new power lines added in 2017 do not help us for our approach and are discarded. The advantage of our strategy is that we hold the policy constant: We have the same power line over the years, the only thing that is changing is its verbal description.

In effect, our data are time-series cross-sectional data with very short time series (2012-2017). We have pooled the (short) time series for each power line that was consulted multiple times. We model the change of the number of participants as dependent on the change of the independent variable (textual complexity of project description).

We add several control variables to our OLS regression models. First, they contain a variable indicating how many submissions mentioned a power line in the last consultation. This variable is important because existing previous mobilization may encourage further mobilization. The length of a power line serves as a proxy for mobilization potential (longer power lines cut through more territory and hence generate more opposition). ${ }^{11}$ Additionally, we add a dummy indicating whether a power line is a new construction or the refurbishment of an old line (new constructions generating more mobilization). A further dummy variable indicates whether a power line is built as a high-voltage direct current $(H V D C)$ transmission line (the so-called

\footnotetext{
11 Alternatively, one might consider the actual population density. However, the proxy length seems plausible. The purpose of the power lines is to bring power to urban areas. That is, each power line has affects at least one populated area. Moreover, the search space for the power lines is very wide (see the example power line description in the appendix), and Germany is densely populated. Hence, all power lines affect at least one densely populated areas, and the longer the lines get, the higher the likelihood that more populated areas are affected.
} 


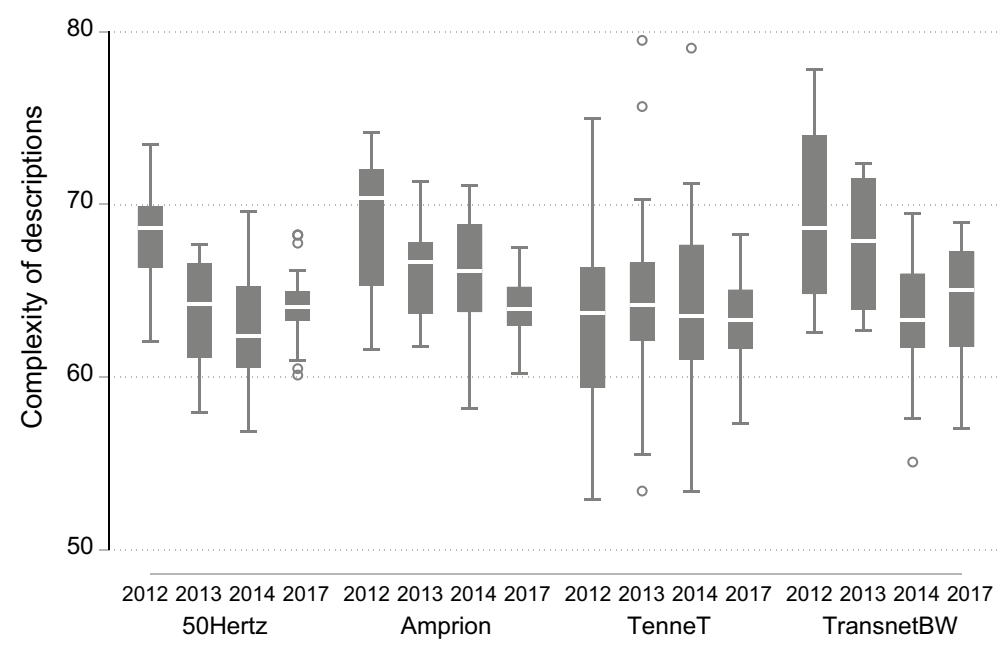

Fig. 1 Linguistic complexity (Lix) of power line descriptions in consultation documents (Network Development Plans, NDPs). Notes: Based on own calculations

"electricity highways", very long power lines, with huge requirements for infrastructure at the start- and endpoints). Alternatively, we introduce dummies for the TSO planning the power line.

Thus, our empirical strategy has upsides and downsides. The upside is that we can hold constant or control for many variables that are thought to influence participation in consultations: The complexity of the policy is constant. The institutional setup remains the same. The downside of our approach is that its generalizability is constrained. First, we have a technical policy field. The complexity of policy descriptions is high, and we may not generalize to "simpler" policy fields. Second, the number of observations is smaller than in comparable studies that study multiple policy fields (Beyers and Arras 2019; Rasmussen and Carroll 2014; Røed and Wøien Hansen 2018). Third, we study only one country, and hence one language.

Thus, we are cautious about generalizing to other countries and other policy fields. However, our study can be seen as a plausibility probe of the idea that language matters for consultation participation.

\section{The empirical analysis}

Our analysis starts with an overview over the complexity of power line descriptions in the demand plans. Figure 1 shows several features. First, the language of the project descriptions is complex. For most years and TSOs, the median Lix for the project descriptions is between 60 and 70. One the one hand, this does not come as a surprise, as the project descriptions are technical documents. On the other hand, the purpose of these consultations is to garner public support for grid construction, and the usual advice is to make consultation documents as easy as possible. This simplification of documents does not seem to have been a priority for the TSOs. Second, 
Table 3 Determinants of change of number of contributions between $t$ and $t+1$

\begin{tabular}{llll}
\hline & $(1)$ & $(2)$ & $(3)$ \\
\hline Change of complexity of & $-19.11^{* *}$ & $-20.05^{* *}$ & $-28.35^{* * *}$ \\
Description & $(9.54)$ & $(9.68)$ & $(9.92)$ \\
Number of contributions & 1.61 & 1.31 & 0.73 \\
last consultation & $(1.56)$ & $(1.48)$ & $(1.55)$ \\
New construction & & 103.67 & \\
& & $(135.97)$ & \\
Length & & $1.15^{*}$ & \\
& & $(0.68)$ & \\
HVDC line & & -114.67 & \\
& & $(357.60)$ & \\
TSO Amprion & & & -78.16 \\
& & & $(179.99)$ \\
TSO TenneT & & & $(174.81$ \\
& & & 256.14 \\
TSO TransnetBW & 41.24 & -176.49 & -48.57 \\
Constant & $(54.52)$ & $(132.85)$ & $(147.68)$ \\
& 68 & 68 & 68 \\
Observations & 0.03 & 0.14 & 0.10 \\
Adjusted $R^{2}$ & & & \\
\hline Standard errors in parentheses. * $p<0.1, * * p<0.05, * * * p<0.01$ \\
\end{tabular}

the large boxes and whiskers of the boxplots indicate variation over projects. There does not seem to be a unified style of project description. Third, there is variation between TSOs. If we take the first NDP as a baseline, Amprion has the most complex project descriptions, TenneT the simplest project descriptions, with the other two TSOs in between. Fourth, there is a pattern over time: The TSOs homogenize their project descriptions. On the whole, median and standard deviation of the complexity scores are decreasing between 2012 and 2017. Thus, it seems that the TSOs are revising their project descriptions to a style that is around a median complexity score of 65 , with decreasing variation if compared to the beginning of the consultations in 2012.

Thus, we have variation of linguistic complexity of project descriptions over the consulting TSOs, over time, and over the grid projects. The question is, whether this variation of complexity has an impact on the pattern of consultation participation. Our theoretical argument claims that linguistically simpler project descriptions attract more consultation contributions commenting on that specific project.

We test this argument with a dynamic model, modeling the change in the number of contributions to a given power line as a function of the change of the complexity of its verbal description. The dependent variable is the change of number of contributions to a given power line between two consultations, e.g., number of contributions in 2013-number of contributions in 2012. Negative values thus indicate a decrease in the number of contributions. The independent variable is the change of the linguistic complexity of the project description. The independent variable is 


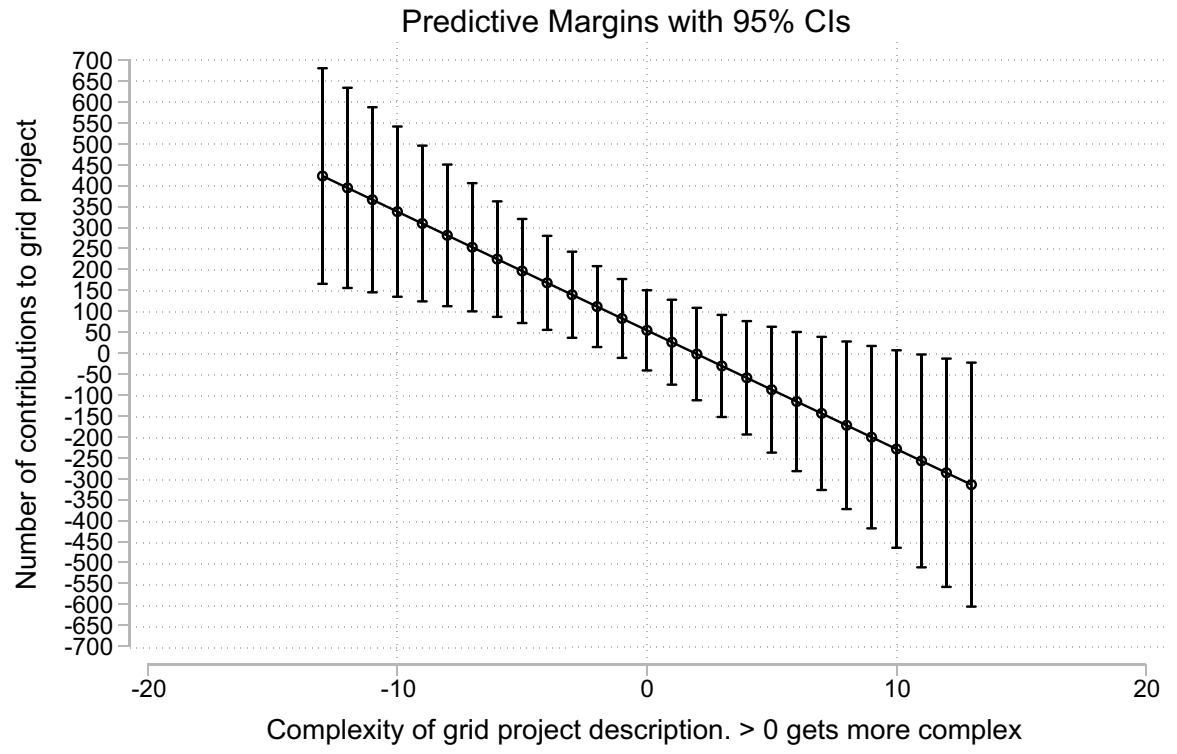

Fig. 2 Predicted number of submissions depending on the complexity of the power line description. Notes: Based on model (1) in Table 3.

constructed as, e.g., complexity of description in 2013-complexity of description in 2012. Thus, negative values denote better readability.

Table 3 shows the results of OLS models. The message is clear: Even if we introduce technical properties of the power line as proxies for the contentiousness of the project, or dummies for the TSOs, the complexity of the verbal description has an impact. The more complex the project is described, the less contributions mention that project.

Figure 2 illustrates the size of the effect. Figure 2 shows first of all, that ceteris paribus all power lines receive more comments over time. Even if the verbal description does not change, the number of contributions increases. However, there is an effect of the complexity of verbal descriptions. Taking the comparison scores of Bischof and Senninger $(2017,481)$, we can state that increasing the complexity by the Lix score of 5 (e.g., from the style of a simple party manifesto to a complex party manifesto), decreases the number of contributions that power line receives by 100 . Although we should not put too much stress on the point estimates- the confidence intervals are large -, the effect is visible: More Complex language of consultation documents is related to substantively less consultation contributions.

Figure 3 illustrates this relationship using actual cases from the dataset. We see two power line projects, P21 and P43. Both have a different level of overall mobilization, but for both, the number of contributions increases as their description becomes simpler.

The project descriptions still are no simple texts. It is an open question what a reduction of a complexity score from 70 to 62 means in substantive terms. One could argue that these texts are still tough to read. On the one hand, the analyses 


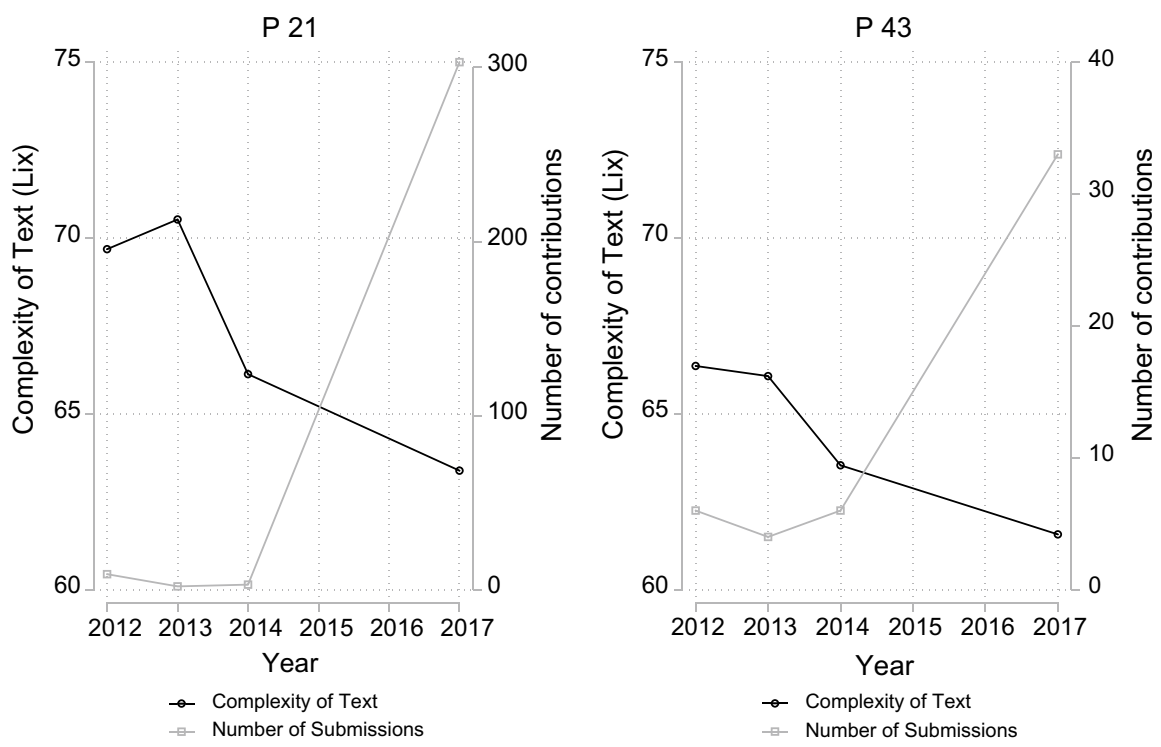

Fig. 3 Empirical examples of relation between linguistic complexity and number of contributions

by Kercher (2013) show a linear effect. Increasing the readability of a political text increases subjective and objective assessments of understanding, that is, people have the impression that they have understood the text better, and they perform better on a test on this text if the language gets simpler. This effect holds over the whole range of readability, that is, making a very hard text "only" hard to read still has an effect. On the other hand, these consideration suggest that the consultation may still not used by everybody. The literature on the demographics of German citizens participating in consultations suggests that these are highly educated men, often with a background in technical jobs (Theocharis and van Deth 2016; Walter et al. 2013, 98-100). While we cannot disentangle participant demographics with our data, the literature suggests that the increase in contributions may be due to highly educated citizens, the sort of people for whom the change from "very hard" to "hard" to read may make a difference.

Further analysis shows that not all types of actors are deterred by complex language. Table 4 shows the same regression as Table 3, model (3), but with different dependent variables: This time we only use the number of contributions by citizens, by citizen initiatives etc. as dependent variables. We see that the effect of readability on the number of contributions is strong for citizen contributions-citizens are deterred by complex language. The effect is also present for citizen initiatives, companies, environmental associations and municipalities. The effect is absent for economic associations, Land administrations and districts. Presumably, both economic associations and Land administrations have a large and professional staff used to working with technical consultation documents. To some extent, this also applies to the German districts that routinely take part in regional infrastructure planning and know the terminology. 


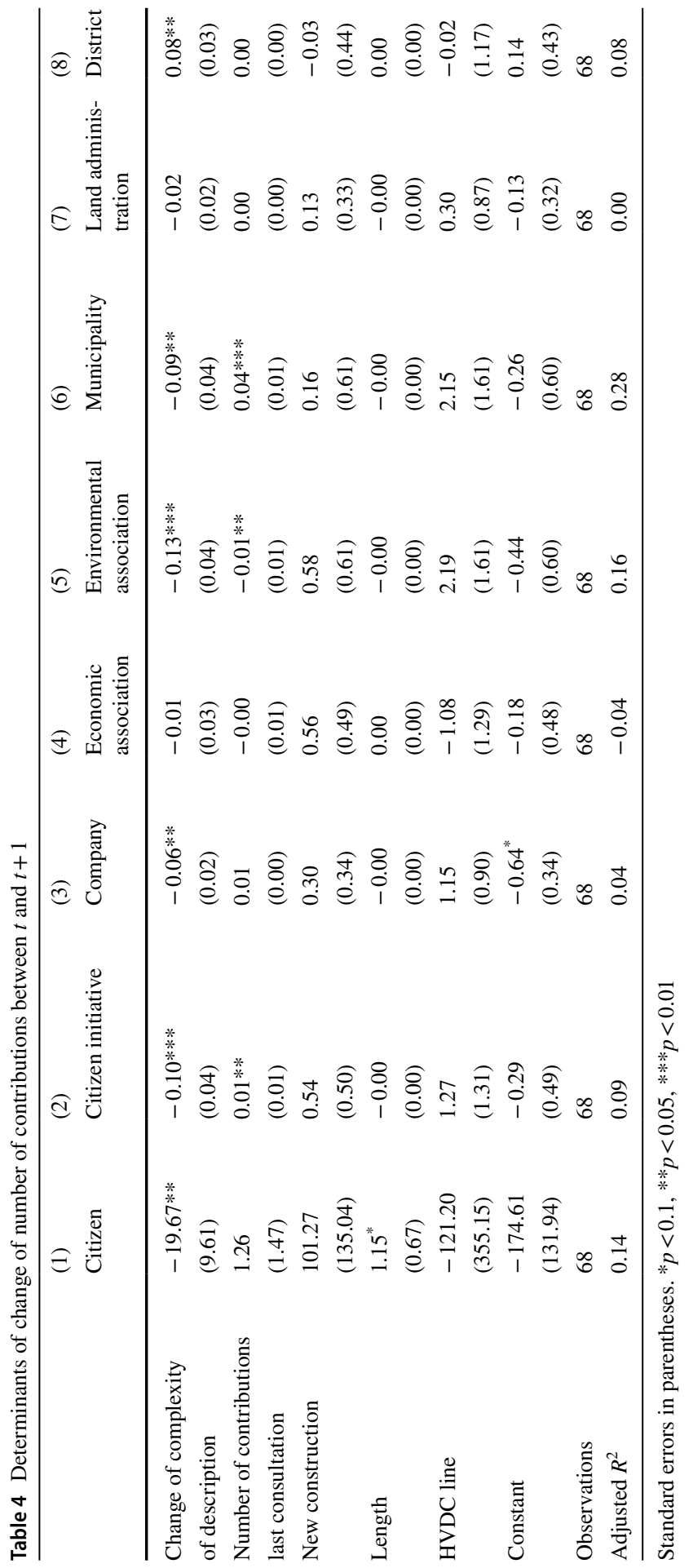


Table 5 Determinants of change of number of contributions between $t$ and $t+1$ using different measures of textual complexity

\begin{tabular}{|c|c|c|c|c|c|c|}
\hline & \multicolumn{3}{|l|}{ SMOG } & \multicolumn{3}{|l|}{ NWS } \\
\hline & (1) & (2) & (3) & (4) & (5) & (6) \\
\hline $\begin{array}{l}\text { Change of complexity } \\
\text { of description }\end{array}$ & $\begin{array}{l}-63.29 * * \\
(31.05)\end{array}$ & $\begin{array}{l}-64.14 * * \\
(30.63)\end{array}$ & $\begin{array}{l}-76.43^{* *} \\
(31.40)\end{array}$ & $\begin{array}{l}-75.38^{*} \\
(40.34)\end{array}$ & $\begin{array}{l}-83.55^{* *} \\
(40.32)\end{array}$ & $\begin{array}{l}-83.62^{* *} \\
(40.53)\end{array}$ \\
\hline $\begin{array}{l}\text { No. of contributions } \\
\text { last consultation }\end{array}$ & $\begin{array}{l}1.21 \\
(1.51)\end{array}$ & $\begin{array}{l}0.91 \\
(1.44)\end{array}$ & $\begin{array}{l}0.26 \\
(1.56)\end{array}$ & $\begin{array}{l}1.30 \\
(1.53)\end{array}$ & $\begin{array}{l}1.05 \\
(1.45)\end{array}$ & $\begin{array}{l}0.40 \\
(1.59)\end{array}$ \\
\hline New construction & & $\begin{array}{l}84.43 \\
(133.97)\end{array}$ & & & $\begin{array}{l}64.58 \\
(132.83)\end{array}$ & \\
\hline Length & & $\begin{array}{l}1.22 * \\
(0.67)\end{array}$ & & & $\begin{array}{l}1.17^{*} \\
(0.67)\end{array}$ & \\
\hline HVDC line & & $\begin{array}{l}-155.51 \\
(351.89)\end{array}$ & & & $\begin{array}{l}-94.95 \\
(360.48)\end{array}$ & \\
\hline TSO 50Hertz & & & $\begin{array}{l}-75.09 \\
(183.44)\end{array}$ & & & $\begin{array}{l}-40.39 \\
(184.13)\end{array}$ \\
\hline TSO Amprion & & & $\begin{array}{l}-36.62 \\
(177.92)\end{array}$ & & & $\begin{array}{l}-1.42 \\
(179.47)\end{array}$ \\
\hline TSO TenneT & & & $\begin{array}{l}185.69 \\
(170.13)\end{array}$ & & & $\begin{array}{l}192.23 \\
(172.24)\end{array}$ \\
\hline Constant & $\begin{array}{l}75.51 \\
(52.61)\end{array}$ & $\begin{array}{l}-130.66 \\
(130.01)\end{array}$ & $\begin{array}{l}36.98 \\
(149.92)\end{array}$ & $\begin{array}{l}41.24 \\
(55.00)\end{array}$ & $\begin{array}{l}-150.43 \\
(130.83)\end{array}$ & $\begin{array}{l}-22.03 \\
(151.35)\end{array}$ \\
\hline Observations & 68 & 68 & 68 & 68 & 68 & 68 \\
\hline Adjusted $R^{2}$ & 0.03 & 0.14 & 0.07 & 0.03 & 0.14 & 0.04 \\
\hline
\end{tabular}

Standard errors in parentheses $* p<0.1, * * p<0.05, * * * p<0.01$

On balance, it seems that not only citizens benefit from simpler consultation documents, but contributions by other actors also increase. This may be due to the technical complexity of the policy field, where only few actors possess the technical knowledge of the TSOs.

An important question of robustness concerns the measurement of textual complexity. To establish a yardstick for comparison with established results (Bischof and Senninger 2017; Kercher 2013), we used the Lix measure. However, there are alternative measures of complexity, such as the simple measure of gobbledygook (SMOG) or the Neue Wiener Sachtextformel (NWS) (Bamberger and Vanecek 1984). The models in Table 5 replicate the models in Table 3, but using the SMOG (models 1-3) or the NWS (models 4-6).

The results of the robustness tests alert us to the fact that measurement matters: In model (4), using the NWS, common standards for statistical significance are not reached. However, in the main models (textual complexity plus variables controlling for technology, or consulting TSO), our results are corroborated.

All in all, we draw a cautious conclusion: Given the low number of observations and the questions of measurement, we do not put too much stress on the 
point estimates. However, our results support the argument that it is worthwhile to look for the relation between textual features of consultation documents and consultation participation. This argument is directly derived from a rational actor model of consultation participation, and it is supported by data in our-albeit limited-policy field.

Our results are partly at odds with the existing literature. Beyers and Arras (2019, 22) do not find a relation between the complexity of language and mobilization of participants. However, our results are not easily comparable, as Beyers and Arras use a hand-coding of only four categories to denote the complexity of language.

Our results are similar to others who find an impact of linguistic properties of political texts. Similar to Bischof and Senninger (2017), who find that citizens can process simpler manifesto messages better, we find that simpler consultation documents cause more mobilization. We also support the argument by Hurka and Haag (2019) that linguistic complexity raises the cognitive transaction costs to read and process documents. Most directly, we corroborate the findings of Røed and Wøien Hansen (2018), who also show a relation between linguistic complexity and decreasing participation. However, our interpretation of the results is different. They use linguistic complexity as a proxy for policy complexity, and argue that more complex policy fields attract less participants. We argue that even given constant complexity of a technical policy field, language of the policy description matters.

In terms of the argument that technically complex policies attract less contributions (Pagliari and Young 2015; Røed and Wøien Hansen 2018), our study is doubleedged. On the one hand, we show that in a technically complex field, easier language helps to attract more contributions. On the other hand, the reverse conclusion also holds: By using complex language, technically complex policies can be presented in a way that allows only a small circle of insiders to participate in consultations.

\section{Conclusion}

Our article argues that current research on participation patterns in consultations may miss one important factor, namely the linguistic complexity of the consultation documents. While there is research on the resources of consultation participants, on the characteristics of the policy under consideration, and on the institutions governing the consultation, there is little research on the linguistic properties of the documents.

Our argument is that the linguistic complexity of consultation documents alters the cost-benefit calculation of participants. This argument is compatible with the dominant rational framework: Linguistic complexity raises the cognitive transaction costs of processing documents. If the documents are too complex, potential participants are deterred from participating, as reading the documents and drafting an appropriate answer is costly, and offers little prospects of success. The argument is not that linguistic complexity is the most important factor determining participation patterns - but it is a factor among many, and a factor that can be influenced by the consulting organization. 
We study the German procedure of electricity grid planning as a test case. This case allows us to hold many factors that are thought to influence participation constant: The overall institutional setting, the policy field, and the pool of potential participants. Moreover, as the consultations are performed annually or biennially, we can use a dynamic model, estimating how a change of the power line description impacts on the change of the number of submissions mentioning that power line.

The results tentatively corroborate our theoretical argument. Increased simplicity of documents is related to more participation. For German grid-planning, this result offers two lessons: Our result suggests first that the procedure is formally a consultation of all power lines, but de facto, power lines described in easier terms attract more contributions, while citizens remain silent if a power line is described in complex language. However, second, there is hope, as consultation documents get simpler.

However, we cannot model every aspect of the mobilization dynamics: We had to exclude one outlier case that generated 7400 contributions, mostly form letters. Thus, our argument applies to the "everyday" dynamics of the consultations, but cannot capture outlier events. Another caveat is the number of cases. There are many power lines in the consultation documents, but to leverage a dynamic perspective, we only used power lines that were consulted repeatedly. This is the price we pay for holding the policy (i.e., the power line) constant.

Moreover, further research is needed, as there are some caveats. Most obviously, we study a technical policy field. Thus, the question is whether we can generalize to other policies. We think, yes. Consultations are often used in technical policy fields, e.g., genetically modified organisms (Ferretti and Lener 2008), regulatory decision making in medicines, aviation, or banking (Beyers and Arras 2019; Pagliari and Young 2015; Rasmussen and Carroll 2014). Moreover, even in supposedly "simpler" policy fields, complex language of consultation documents could be used to obfuscate distributional consequences. A different question is whether we can generalize beyond the German language. Theoretically, our argument is abstract: Linguistic complexity in any language generates cognitive transaction costs for potential consultation participants. Empirically, however, research on cross-lingual readability assessment is only in its beginnings (Madrazo Azpiazu and Pera 2020).

Taking into account these caveats, our article shows the plausibility of the argument that language matters. The prescriptive literature argues that consultation documents should be easy to understand, but has never tested whether actual consultation documents are easy to understand. Our article shows a way to assess the readability of consultation documents and builds a bridge between normative reasoning and empirical research.

\section{Appendix}

See Table 6. 
Table 6 Submissions per power line, disaggregated into actor type contributing

\begin{tabular}{llrll}
\hline & \multicolumn{4}{l}{ Submissions per power line } \\
\cline { 2 - 5 } & Mean & SD & Min & Max \\
\hline Citizens & 63.58 & 501.29 & 0 & 7241 \\
Citizen initiative & 1.47 & 5.38 & 0 & 30 \\
Company & .77 & 2.67 & 0 & 14 \\
Economic association & .64 & 2.04 & 0 & 10 \\
Environmental association & .80 & 2.34 & 0 & 11 \\
Municipality & 2.41 & 9.35 & 0 & 87 \\
Land administration & 1.03 & 2.48 & 0 & 13 \\
District & .82 & 2.16 & 0 & 14 \\
\hline
\end{tabular}

Funding Open Access funding enabled and organized by Projekt DEAL.

\section{Declarations}

Conflict of interest On behalf of all authors, the corresponding author states that there is no conflict of interest.

Open Access This article is licensed under a Creative Commons Attribution 4.0 International License, which permits use, sharing, adaptation, distribution and reproduction in any medium or format, as long as you give appropriate credit to the original author(s) and the source, provide a link to the Creative Commons licence, and indicate if changes were made. The images or other third party material in this article are included in the article's Creative Commons licence, unless indicated otherwise in a credit line to the material. If material is not included in the article's Creative Commons licence and your intended use is not permitted by statutory regulation or exceeds the permitted use, you will need to obtain permission directly from the copyright holder. To view a copy of this licence, visit http://creativecommons.org/licen ses/by/4.0/.

\section{References}

Arras, Sarah and Jan Beyers. 2020. "Access to European Union Agencies: Usual Suspects or Balanced Interest Representation in Open and Closed Consultations?" JCMS: Journal of Common Market Studies 58 (4): 836-855.

Arras, Sarah, and Caelesta Braun. 2018. Stakeholders wanted! Why and how European Union agencies involve non-state stakeholders. Journal of European Public Policy 25 (9): 1257-1275.

Balla, Steven J. 1998. Administrative Procedures and Political Control of the Bureaucracy. The American Political Science Review 92 (3): 663-673.

Bamberger, Richard and Erich Vanecek. 1984. Lesen, verstehen, lernen, schreiben : die Schwierigkeitsstufen von Texten in deutscher Sprache. Wien [u.a.]: Jugend und Volk [u.a.].

Beyers, Jan and Sarah Arras. 2019. "Who feeds information to regulators? Stakeholder diversity in European Union regulatory agency consultations." Journal of Public Policy: 40, 1-26.

Bischof, Daniel, and Roman Senninger. 2017. Simple politics for the people? Complexity in campaign messages and political knowledge. European Journal of Political Research 57 (2): 473-495.

Björnsson, Carl-Hugo. 1968. Läsbarhet. Stockholm: Bokförlaget Liber.

Bouwen, Pieter. 2002. Corporate Lobbying in the European Union: The Logic of Access. Journal of European Public Policy 9 (3): 365-390. 
Broscheid, Andreas, and David Coen. 2007. Lobbying Activity and Fora Creation in the EU: Empirically exploring the Nature of the Policy Good. Journal of European Public Policy 14 (3): 346-365.

Bunea, Adriana. 2017. Designing stakeholder consultations: Reinforcing or alleviating bias in the European Union system of governance? European Journal of Political Research 56 (1): 46-69.

Bunea, Adriana, and Robert Thomson. 2015. Consultations with Interest Groups and the Empowerment of Executives: Evidence from the European Union. Governance 28 (4): 517-531.

Ferretti, Maria Paola, and Matteo Lener. 2008. Lay Public or Experts? e-Participation in Authorization for GMO Products in the European Union. Review of Policy Research 25 (6): 507-525.

Fink, Simon, and Eva Ruffing. 2019. Going beyond dyadic consultation relationships: information exchange in multi-step participation procedures. Journal of Public Policy 39 (4): 587-608.

Fink, Simon, and Eva Ruffing. 2020. "Learning in iterated consultation procedures-The example of the German electricity grid demand planning." Utilities Policy early view.

Heidbreder, Eva G. 2015. Governance in the European Union: A Policy Analysis of the Attempts to Raise Legitimacy through Civil Society Participation. Journal of Comparative Policy Analysis: Research and Practice 17 (4): 359-377.

Hermansson, Henrik. 2016. The European Commission's environmental stakeholder consultations: Is lobbying success based on what you know, what you own or who you know? Interest Groups \& Advocacy 5 (3): 177-199.

Hurka, Steffen and Maximilian Haag. 2019. "Policy complexity and legislative duration in the European Union." European Union Politics: 1465116519859431.

Kercher, Jan. 2013. "Verstehen und Verständlichkeit von Politikersprache : Verbale Bedeutungsvermittlung zwischen Politikern und Bürgern."

Klüver, Heike. 2013. Lobbying as a Collective Enterprise: Winners and Losers of Policy Formulation in the European Union. Journal of European Public Policy 20 (1): 59-76.

Kohler-Koch, Beate, and Barbara Finke. 2007. The Institutional Shaping of EU-Society Relations: A Contribution to Democracy via Participation? Journal of Civil Society 3 (3): 205-221.

Azpiazu, Madrazo, and Ion and Maria Soledad Pera. . 2020. Is cross-lingual readability assessment possible? Journal of the Association for Information Science and Technology 71 (6): 644-656.

OECD. 2001. Citizens as Partners. Information, Consultation and Public Participation in Policy-Making. Paris: Organisation for Economic Co-operation and Development.

Pagliari, Stefano, and Kevin Young. 2015. The interest ecology of financial regulation: interest group plurality in the design of financial regulatory policies. Socio-Economic Review 14 (2): 309-337.

Pakull, Dominic, David Marshall and Patrick Bernhagen. 2020. "Shop till you drop? Venue choices of business and non-business interests in the European Union." Interest Groups \& Advocacy.

Rasmussen, Anne, and Brendan Carroll. 2014. Determinants of Upper-class Dominance in the Heavenly Chorus: Lessons from European Commission Online Consultations. British Journal of Political Science 44 (2): 445-459.

Rasmussen, Anne, Carroll Brendan, and Lowery David. 2014. Representatives of the Public?: Public Opinion and Interest Group Activity. European Journal of Political Research 53 (2): 250-268.

Røed, Maiken and Vibeke Wøien Hansen. 2018. "Explaining Participation Bias in the European Commission's Online Consultations: The Struggle for Policy Gain without too Much Pain." JCMS: Journal of Common Market Studies 56 (6): 1446-1461.

Saurugger, Sabine. 2010. The social construction of the participatory turn: The emergence of a norm in the European Union. European Journal of Political Research 49 (4): 471-495.

Schmidt, Vivien A. 2012. Democracy and Legitimacy in the European Union Revisited: Input, Output and 'Throughput.' Political Studies 61 (1): 2-22.

Sjoberg, Fredrik M., Jonathan Mellon, and Tiago Peixoto. 2017. The Effect of Bureaucratic Responsiveness on Citizen Participation. Public Administration Review 77 (3): 340-351.

Smith, Graham. 2009. Democratic Innovations: Designing Institutions for Citizen Participation. Cambridge: Cambridge University Press.

Steinbach, Armin. 2013. Barriers and Solutions for Expansion of Electricity Grids-the German Experience. Energy Policy 63: 224-229.

Theocharis, Yannis and Jan van Deth. 2016. "The continuous expansion of citizen participation: a new taxonomy." European Political Science Review online first.

Van Ballaert, Bart. 2017. "The European Commission's use of consultation during policy formulation: The effects of policy characteristics." European Union Politics: 1465116517702004. 
Walter, Franz, Stine Marg, Lars Geiges, and Felix Butzlaff. 2013. Die neue Macht der Bürger. 1. Aufl. Reinbek bei Hamburg: Rowohlt.

Yackee, J.W., and S.W. Yackee. 2006. A bias towards business? Assessing interest group influence on the US bureaucracy. Journal of Politics 68 (1): 128-139.

Publisher's Note Springer Nature remains neutral with regard to jurisdictional claims in published maps and institutional affiliations. 